\title{
Article
}

\section{Coolification and Language Vitality: The Case of Esperanto}

\author{
Federico Gobbo (1)
}

check for

updates

Citation: Gobbo, Federico. 2021. Coolification and Language Vitality: The Case of Esperanto. Languages 6: 93. https://doi.org/10.3390/ languages6020093

Academic Editor: Marco Tamburelli

Received: 29 January 2021

Accepted: 14 May 2021

Published: 21 May 2021

Publisher's Note: MDPI stays neutral with regard to jurisdictional claims in published maps and institutional affiliations.
Amsterdam Center for Language and Communication, University of Amsterdam, 1012 VB Amsterdam, The Netherlands; f.gobbo@uva.nl

\begin{abstract}
Despite experiencing a relatively positive revival in the digital age, Esperanto and the assessment of its language vitality is often problematic and prone to gross errors; therefore, a theoretical reflection is required. Unlike other lesser-used languages, Esperanto is intergenerationally transmitted mainly outside the family, and so Fishman's GIDS and subsequent scales such as the EGIDS cannot be applied straightforwardly for language vitality diagnosis and estimation. In particular, it is the social movement of language activists who have guaranteed Esperanto's vitality and development for more than a century. A key aspect is the digital domain, where, paradoxically, the relatively good positioning of Esperanto in terms of new users does not imply a parallel increase in the number of activists. This paper critically assesses the digital language vitality of Esperanto on the basis of its language ideology and other sociolinguistic data as a starting point for a discussion to overcome the limits of Blanke's (2006) scale of language vitality of Esperanto and its rivals (in the sense of Garvía 2015). This assessment eventually leads to a more general reflection on the role of 'coolification', i.e., positive effects on language attitudes and development due to digital visibility, its limits and the issue of placing it in the context of language vitality in general.
\end{abstract}

Keywords: language vitality; digital language vitality; Esperanto; coolification; intergenerational transmission

\section{Introduction}

To what extent digital technologies foster the vitality of lesser-used languages is still unclear. Experiences from different languages throughout the world elicit good practices, from which scholars and language activists have published documents on how to take more effective action in the digital realm, such as the guideline prepared by the First Peoples' Cultural Council (2020) for indigenous languages and by the institute for endangered languages (Daigneault et al. 2020). This paper aims to contribute to the ongoing discussion on the digital dimension of language vitality from the perspective of planned languages in general and Esperanto-the most developed one-in particular. Although rarely taken into account, planned languages offer an interesting case study as, by definition, they come into existence through the publication of a written standard variety. In the field of current digital technologies, planned languages are, in some respects, different from other lesser-used languages; we will briefly mention only the most evident issues (also, Astori 2018). First, there is no issue in finding — or deciding not to find - an orthography among different writing systems already spontaneously in use, as the orthography comes off the shelf from the start. Second, there is no need to choose or plan a prestigious variety, dialectical variation being either irrelevant (Esperanto) or totally non-existent (in the case of Esperanto rivals).

Apart from these rather technical traits, planned languages lack any myth of ancestry and authenticity (for a sociolinguistic classification, see Stewart 1968). This fact has immediate consequences in the language attitudes of their speakers and their perception from an external point of view. First, planned languages are not linked to a particular territory, ethnic group, or past history. Second, first-language speakers-among planned languages, present only in the case of Esperanto-do not hold a special authority; in other words, 
there is no friction between 'the whole mystique of native speakers' already questioned by Ferguson (1982) and new speakers. In fact, in the case of planned languages, all speakers are new-in the 'post-traditional' sense used by Costa (2015) for Provençal. In particular, they are often involved in the production of original cultural products in the language, most notably original songs of various genres (from heavy metal to reggae). A possible exception is Esperanto family speakers, who are, indeed, a tiny minority, in quantitative terms (for a discussion, see Fiedler 2012). The peculiar status of Esperanto speakers is the source of its contestedness (in the sense of Tamburelli and Tosco 2021), e.g., it is accused of being "artificial", "dead" or "parasitic", not having prototypical monolingual speakers of its own.

This paper proceeds as follows: After a brief presentation of the language attitudes of Zamenhof, the founder of Esperanto (Section 2), and a summary of the language attitudes speakers have developed until today, which are quite different from Zamenhof's (Section 3), the paper illustrates the digital presence of Esperanto (Section 4) and discusses why the scales proposed for measuring the vitality of lesser-used languages cannot be used as such in the case of planned languages (Section 5). Finally, Section 6 draws insights from the case study analysis in the broader perspective of identity-building and language representation.

\section{Zamenhof's Vision for the International Language}

In 1887, Ludwik Lejzer Zamenhof published the structure of his language project in Warsaw, in a small book in Russian, that eventually became known under the name of Esperanto (Zamenhof 1887). Originally, Zamenhof called his language project lingvo internacia, t.e. 'international language' (Gobbo 2016). However, for him, this expression does not refer to a language widely spread across the world and used by native and nonnative speakers to communicate (for example, English or French), but to something more radical than using a language belonging to a powerful nation. Echoing the myth of the Tower of Babel, 'the human family was divided' and 'a never-ending war started' because of two causes: the plurality of religions and languages (Dietterle 1929, p. 361). Therefore, in his conceptualisation, elaborated in his public speeches collected in Dietterle (1929), a "just" international language should be detached from ethnicity, i.e., it should not belong to any special people or ethnic group-he used the Esperanto word gento, recalling the Latin word 'gens'.

The first target group of interest to him was Jewish people, Zamenhof being a litvak Ashkenazi (Fishman 1996; Korzhenkov 2010), for whom he envisioned a reform of the Covenantal Judaism that he called Hillelism-see Schor (forthcoming, 2010). Such an enlightened reform should act as a natural bridge between Jewish and non-Jewish people, and this 'neutral ground' (neŭtrala fundamento, in Dietterle 1929, p. 314 et passim) should be realised under the form of 'round circles and temples', starting from the cities of 'neutral Switzerland' (in Dietterle 1929, p. 312 et passim). Hillelism was essentially a failure, and even Homaranism, the second version of the project-in essence, a moral philosophy for the individual, close to Kant's categorical imperative-had no great fortune, neither among Jewish people nor Esperanto speakers in general. Thus, by 1906, Zamenhof clearly disentangled the religious and linguistic aspects of his project, declaring that 'we should not intermix Hillelism with Esperantism! Both ideas are closely related one to the other, although not entirely identical' (in Dietterle 1929, p. 315, footnote *).

Zamenhof had no particular trust in politics and politicians, since he realised that ethnic conflicts are found both in empires-for example, Tsarist Russia and Austria-Hungaryand in nation-states-such as France or Germany. An indirect proof of this fact is his withdrawal from the Zionist movement by 1882, when he was a university student. In 1881, the Palestinian option for settling in the new state of Israel definitely overcame its political proposal, i.e., settling a state inside the United States of America on the Mississippi river, similarly to what Mormons did in Utah (Esperanto version of the Russian original in Kanzi 1976). Zamenhof (1915) formulated his political testament as an appeal to diplomats, published bilingually in Esperanto and English, in which he advocated for the 'United 
States of Europe', suggesting a language policy of 'neutral names' of countries and cities in Esperanto across the continent in order to set a common linguistic ground for the new super-national institution to be formed after the end of the war.

In sum, the role of Esperanto, envisaged by its founder, was to be a shield against 'chauvinism', which he considered a degeneration of patriotism, i.e., the 'natural love of one's country' (in Dietterle 1929, pp. 382-83). The 'international language' should be a 'neutral-human ground', fundamento neŭtrale-homa, where individuals from different ethnic origins put their respective national identities in the background, forming literally 'one great familiar circle', unu grandan rondon familian, which is a key passage of his fundamental poem La Espero, The Hope (in Dietterle 1929, p. 586). In other words, Zamenhof's vision was that Esperanto should be a stepping-stone to achieving human brotherhood beyond national identities, which was the core of first Hillelism and then Homaranism. Needless to say, he did not see his vision realised, and neither do we nowadays.

\section{Esperanto in the 21st Century: A Language in Search of an Identity}

What does remain of Zamenhof's vision in today's Esperanto Movement is admittedly not much. There are many language ideologies fostered by Esperanto supporters and speakers, and they differ especially in their relation to national identities and the place of Esperanto in a multilingual panorama. What they have in common is some version of the 'internal idea', interna ideo, which is the expression Zamenhof used to indicate the use of Esperanto to realise 'brotherhood and justice between all people' (my translation from Dietterle 1929, p. 372). What this 'internal idea' means exactly depends on the times and cultural milieux in which the Esperanto speakers find themselves, as well as the uninterrupted tradition formed by the ideologies that the Esperanto intellectuals formed in more than a century of use-for an overview, Gobbo (2017).

It was the Esperanto Movement in France that transformed La Espero into a pseudonational anthem in the crucial 'vertigo years' (as Blom 2008) at the dawn of the new century (1900-1914). Eventually, French Esperantists applied the rhetoric of a national uprising to Esperanto, only applied to a worldwide scale. In the long run, the French way to Esperanto led Mark Fettes (1996) to formulate the conception of the Esperanto community as a 'quasi-ethnic' minority, then reprised and elaborated in particular by Melnikov (2015) and Astori (2016).

Such a conception of Esperantists being a "pseudo-people" is partially reflected in the Manifesto published in the World Esperanto Congress in Prague in 1996, the drafting of which was carried out by Fettes himself, with others. This Manifesto was never seriously challenged or called into question afterwards; therefore, it can be considered representative of the mainstream Esperanto ideology and identity. There, the digital factor is completely absent, not to mention previous documents influencing the strategy of the Esperanto Movement. Surprisingly enough, the growth of interest in language learning through digital tools did not spark interest to reconfigure the objectives of the Esperanto Movement in a new programmatic document by the new generation of speakers, at least up to now. In introducing the Millennials or Generation Y (born 1980-2000) as a distinct sub-group, Rainer and Rainer (2011, p. 173) argue that they have 'clear convictions' about 'issues like same-gender marriages and environmental actions' which go beyond national borders, if not embracing the whole planet, and therefore, may be a fertile ground for Esperanto as a global endeavour. The relative popularity of online Esperanto courses seems to confirm this impression; however, their long-term effects were recently discussed inside the community.

While Chuck Smith, the Esperantist of the Year 2015, could say then that everyday, 30 people across the world, found especially in the US, finished the Esperanto Duolingo course (Smith 2015), five years later, Robert Nielsen (2020), a major language activist belonging to the Millennials, complained that there are 2.8 million people enrolled in the Esperanto Duolingo course - via English, Spanish, and Portuguese-but 'very few' pass to 'the other side' and enter the Esperanto community. As a final note, from 2020, Esperanto speakers-like all the rest of humanity-are fronting new issues for the severe limitations 
in physical mobility that are a prerequisite of real-world gatherings, due to the global COVID-19 pandemic. This may lead to a bias, i.e., the overestimation of the digital use of lesser-used languages in general, simply because of a lack of alternatives. In the following section, the use of Esperanto in the digital domain will be illustrated through the Digital Language Vitality Scale (DLVS) proposed by Ceberio et al. (2018).

\section{Lessons Learnt from Esperanto and Digital Vitality}

The case of Esperanto is particularly interesting as the language is detached from any specific proper identity-building territory (Sprachraum), claiming to be a 'world language', thus being at ease on the World Wide Web. Preliminary research shows that digital presence is a key factor for the 'coolness factor', especially when producing original content or adding specific information that helps construct language identity, instead of merely translating information from other languages. Esperanto gives evidence of good practice; for instance, in comparison with Piedmontese, Gobbo and Miola (2016) notice: "thus, writing Wikipedia pages with original content would be a more relevant and smarter move than translating from Wikipedias in other languages, as the rich and original resources on Zamenhof or linguistics (lingvistiko) show in the Esperanto Wikipedia" (298, my translation from Italian). However, it is still open to discussion how far the process of 'coolification' eventually helps maintain, or actually promotes, the language as a whole. Ceberio et al. (2018) give recommendations on how to assess - and improve-the digital capacity, presence and performance of a language under scrutiny.

In terms of availability of internet media, it is important to consider that the majority of Esperanto speakers are digitally literate, especially the Millennials (see above for a definition). Not surprisingly, the presence and visibility of language mentors, activists and disseminators creating original digital content is far from neglected. The size and activity rates of the Esperanto Wikipedia are remarkable, at least in terms of visibility: activists and the public generally look at the raw number of entries, which is undoubtably remarkable-more than 291 thousand articles up to January 2021 (for a discussion, see van Dijk 2009). Apart from Wikipedia, Esperanto speakers can use Facebook, Wordpress or Telegram in the language; part of these translations are supported through the initiative Instigo-Liberapay, whose aim is 'to provide online services in Esperanto and other satellite activities' (source: liberapay.com/instigo; accessed on 10 May 2021), under the auspices of the Universal Esperanto Association.

Graphisation of the language, which is an issue open to debate in the case of many lesser-used languages (e.g., Miola 2015 on Piedmontese), is not particularly problematic in the case of Esperanto. The encoding of the flag characters of Esperanto $<\hat{c}, \hat{g}, \hat{h}, \hat{J}, \hat{s}$, $\breve{\mathrm{u}}>$ is guaranteed with free add-ons in the major operating systems of computers (both proprietary and free) as well as mobile devices, and especially telephones, avoiding the risk of the 'tyranny of the keyboard', as Miola (2015) defined it. Interestingly, the debate on the opportunity (or not) of an orthographic reform for Esperanto, which was still very lively in the 1980s, as Large (1985) and especially Forster (1982) attested, is now almost forgotten, thanks to technological changes.

The making of e-dictionaries requires not only interfaces in the language, but also ad hoc software. People may install Linux in Esperanto and find (video) bloggers explaining various topics, not only language-related, and sometimes in the form of tutorials. There are spell checkers available for Esperanto in the realm of free software ${ }^{1}$, such as Esperantilo, and the popular suite LibreOffice is completely translated into the language. Tools for Part-of-Speech and syntactic tagging are still limited, even if the transparent syntactic marking of Esperanto permits a relatively high quality in machine translation tools, both in proprietary software (such as Google Translate) and free ones (such as Apertium). Additionally, there are a few corpora, but only of written use. The most used one, which is better maintained and updated by a leading figure of the social movement, is called

1 Broadly, free software is non-proprietary, so that anybody is allowed to modify its source code to improve its functionality. 
Tekstaro: by now, it has approximately 10.4 million words (see Wennergren 2021; last major update: 2018), which, in absolute terms, makes Tekstaro a small corpus, as the benchmark used in corpus linguistics for a larger corpus is usually 100 million words. This paucity is counterbalanced by a rich and updated monolingual e-dictionary called Vortaro, and a conspicuous presence of bilingual e-dictionaries, even in not-so-large languages, such as Basque and Catalan. It should be noted, however, that most bilingual Esperanto dictionaries are still published on paper only, even very recently-e.g., the Lithuanian one edited by Čeliauskas and Puodènas (2018).

A thorough scrutiny of the position of Esperanto in the digital realm would go beyond the scope of this paper, which aims to illustrate the role and limit of digital presence and use in promoting the vitality of lesser-used languages, through the lens of the Esperanto case. It comes not entirely by surprise that the application of the DLVS can lead to paradoxical results. In sum, in terms of active production and use of digital tools, Esperanto could even be put on level 4 (Developing), but on the other hand, the tools for NLP are still underdeveloped, more on level 2 (Dormant). As a working hypothesis, Esperanto is suitable for level 3 (Emergent); however, a more in-depth analysis would be needed to assess it through robust, and hopefully longitudinal, data. Table 1 illustrates the initial assessment of Esperanto in terms of the DLVS made so far.

Table 1. The digital language vitality assessment of Esperanto (following Ceberio et al. 2018).

\begin{tabular}{ccc}
\hline Parameter & Label & Score \\
\hline Digital Capacity & & 2 \\
Evidence of connectivity & good & 2 \\
Digital literacy & basic & 2 \\
Internet penetration & good & 6 \\
Character encoding & supported & 3.5 \\
Availability of language resources & limited & 5 \\
Use for e-communication & strong & 5 \\
Availability of Internet media & strong & 6 \\
Digital Performance & strong & 5 \\
Availability of Internet services & medium & 4 \\
Localised social networks & medium & 6 \\
Localised software & advanced & 3 \\
Machine translation tools & no & \\
\hline
\end{tabular}

1 This score is tentative; see remarks infra-text for details.

Assessment of the digital vitality of Esperanto shows that activists are certainly lively and passionate, but their actions are rarely coordinated to obtain robust outcomes, especially in the field of e-dictionary making. The underlying working hypothesis is that, while merely translating documents for existing software can be performed by isolated individuals, long-term results for software development and corpora use could profit from collective efforts by high-skilled training for language activists, eventually lifting the target language up in the DLVS. For the purposes of the usage of the scale, the application of the DLVS to Esperanto did not pose particular problems, with one exception, i.e., the assessment of availability of language resources. In fact, the distance between values 3 and 4 in such variable is quite distant and may require a revision or at least a clarification by the authors. A more in-depth analysis of the limitations of the DLVS-as well as scales in general, in order to measure language vitality—is postponed until the final discussion (Section 6).

\section{How to Measure the Language Vitality of Esperanto and Its Rivals}

In the field of Interlinguistics, traditionally devoted to the comparison between international auxiliary languages such as Esperanto and its rivals, Detlev Blanke $(1985,1989)$ proposed a scale measuring the "socialization process" of such languages in 19 steps, 
indicating that "the only planned language which really has functioned, up to now, is Esperanto" (Blanke 1989, p. 70). He then revised the scale in 2006, which presents 27 steps. Although they are undoubtably informative, Blanke's scales cannot be applied as such in order to assess the current situation of Esperanto and other planned languages, as the role reserved to its digital use is either absent (in the first version of 1985/1989) or very marginal (in the revision of 2006). In the following, we revise the main points of Blanke's (2006) scale in comparison with Fishman's GIDS and its extended version EGIDS, having in mind the previous assessment of the terms of DLVS. The aim is to propose a new scale of language vitality for planned languages in general and Esperanto in particular, which includes the digital domains, without overestimating their role.

The rationale behind the construction of the original Graded Intergenerational Disruption Scale (GIDS) was stated very clearly by Fishman (1991): "the higher the GIDS rating the lower the intergenerational continuity and maintenance prospects of a language network or community" (p. 87). Such a principle is retained in its extended version, which is currently in use - the EGIDS (Lewis and Simons 2010). Unlike most languages in the world, intergenerational continuity in the case of Esperanto mainly passes not through family use, but through language activists passing their knowledge and involvement onto the next generation. By definition, planned languages violate what Lyons called 'the historical priority of speech over writing' (Lyons 1981, p. 12), sign languages being the other example of a violation. Unlike lesser-used languages across the world, the ultimate goal is not to obtain an accepted formal variety in wide use among existing and new speakers, but to form a community of speakers starting from a prescriptive variety, initially only written on paper, that should be the guideline for the standard language, and eventually, becomes the flag of its legitimacy, in the sense of Milroy (2001). For this reason, there will never be a correspondence of stage 8 of the GIDS, as, in the case of planned languages, 'vestigial users' or 'socially isolated old folks' are never found (Fishman 1991, p. 88). Although demographics show that retirees were always present in the Esperanto Movement since the first sociological surveys (reprised by Garvía 2015, Chapter 12), they were never isolated in Fishman's terms, thanks to writing: even in the pioneers' generation (1887-1905), Esperanto was mainly used for correspondence in written form, often publicly available through the first periodic in the language, La Esperantisto (Haupenthal 1988; Dietterle 1929).

The whole point of Esperanto-and most planned languages-has always been to connect with other users across barriers, no matter if they are geographical or cultural. In order to be used, the language should be stable; in other words, its basic structure should be stated clearly enough in order to be ready for use by people other than the original proponent. In the terms of Blanke (2006), the prerequisite of usage is the step from the stage of being a manuscript (step 1) to a Plansprachprojekt, a language project (step 2), which implies a publication of some sort-a brochure, a web site, or other forms. History shows that language projects heavily rely on the leading figure of the proponent, which is to say that they may not survive him-'him', planned languages being proposed in their vast majority by men, not women (for a review, Eco 1996). Blanke's steps 3-7 illustrate the main actions to be carried out in order to make the figure of the proponent no longer necessary. This goal is achieved by producing publications in and about the language, such as: teaching instruments (step 3) to let activists acquire the language; propagandistic or apologetic texts, justifying the need or opportunity to learn the language (step 4); periodicals for producing basic texts that guide the early adopters in their language use (step 5); correspondence (step 6); translated and original texts of literature in the sense of belle lettres (step 7).

It is questionable whether Blanke's steps are followed in the exact order he envisaged; however, what is certain is that the establishment of a language project initially passes through the sharing of the language in written use. For the initial testing of the project, there is no essential difference between old-fashioned postcards and email messages, nor between brochures and blogs. What has changed nowadays is the possibility to immediately produce audio and video material directly in the language and for free; one 
century ago, when Esperanto and its rivals were proposed and discussed, at least by the intellectual élites and social avant gardes, this possibility was unthinkable (Garvía 2015). While written standardization is often a goal for languages escaping danger, in the case of planned languages, the challenge is orality.

Fishman (1991, p. 92) states that the first major passage in the GIDS is reaching step 6 , when "the younger generation ... leave behind an already ongoing sociolinguistic modus vivendi", adopting the lesser-used language to guarantee intergenerational transmission. The EGIDS makes a further step, specifying that the trend in the number of users is crucial to pass from the status of being threatened (step 6b) to vigorous (step 6a; Lewis and Simons 2010). To reprise the original example by Fishman (1991, p. 92), there is no Esperanto counterpart to "pioneering Jewish settlements in late nineteenth and early twentieth century Palestine". In other words, there are no primary schools, nor a stable public linguistic landscape, nor any other basic service for everyday public life, such as the post office or grocery market, in Esperanto, anywhere. Esperanto families gather in specific meetings - always in Europe-but they do not live together. In other words, paraphrasing Fishman's terms, they form families but they do not attain community. Interestingly, the emphasis put on the 'Esperanto native speakers', denaskuloj, a heavily ideologically loaded term to indicate Esperanto family speakers, is an emergent phenomenon in the language's representation by the younger generations (Caligaris 2016). However, such a trend is still at an infancy stage, and it should be confirmed by the developments shown inside the community in the coming years. By now, there is no sign of concrete projects struggling to live together to settle in "Esperantoland", for the ideological reasons illustrated above-see also Gobbo (2017).

Does this sociolinguistic profile mean that Esperanto is a threatened language, and therefore, it should be placed in step $6 \mathrm{~b}$ of the EGIDS? Arguably, not, as it is without any doubt that Esperanto is mainly used between people from different cultural backgrounds in knowledge exchange, which is one of the traits for achieving the status of 'international language' (stage 0), the highest possible stage in the EGIDS. Simply put, Esperanto does not fit the scales based on in-family intergenerational transmission. We need to take a different perspective in analysing the bonds that connect Esperanto speakers together. Blanke's scale indicates the community-building phase as the major passage for planned languages: a lively community permits passing from the status of a language project to the status of Semiplansprachen (Blanke 2006, p. 71), which sounds like 'semilanguages' in English (Blanke 1989). Since step 8, Mündliche Kommunikation, worldwide communication, the formation of a network of local clubs scattered through the world is the first move in establishing the social movement, then expressed under the form of a registered, nongovernmental organisation (with fees and services to the members) and culminating in the formation of 'a small community' (Kleine Sprachgemeinschaft, step 12), based on 'personal contacts' between the adherents. In terms of Social Network Theory (SNT), Blanke's indication may correspond to the formation of strong and weak ties, in which the common language is the fil rouge that ultimately ties the speakers, which results in "the combination of amount of time, the emotional intensity, the intimacy (mutual confiding) and the reciprocal services which characterize the tie" (Granovetter 1973, p. 1361). As a working hypothesis, the immediate feeling of trust among comrades speaking Esperanto, even if they have never met before, that informants report anecdotally in participant observation over twenty years, suggests that the ties between Esperanto speakers may be either weak or strong. Unfortunately, extensive sociological or longitudinal studies to corroborate such a hypothesis are still not available.

Blanke's term 'semilanguage' is unfortunate, as it may suggest that the planned language is used only by semi-speakers, i.e., that there is nobody who has full competence of the language, which is not necessarily true. According to him, few traditional major rivals of Esperanto - in particular, Ido, Interlingue (ex Occidental), and IALA's Interlinguaare 'semilanguages'. In the last few decades, the aforementioned languages have gained some visibility thanks to digital resources, so it seems appropriate to use the DLVS for 
an initial assessment of their vitality in general. Participant observation shows that these languages have tiny support ( $<1000$ users) from a bunch of isolated activists whose main activity is to update their websites, Wikipedia, and to translate the user interfaces of means of digital communication; however, in general, outputs are very limited, due to lack of human resources. For this reason, the working hypothesis is that they fit level 2 of the DLVS (i.e., Emergent), in the best case.

I propose here to use the term 'awakening languages' instead of 'semilanguages', as ultimately, planned languages in such a stage are mainly strengthening the ties of the social network established in step 12. In particular, in the upper steps of Blanke's (2006) scale, the digital dimension of language vitality shows its anachronism and arbitrariness: for instance, Blanke (2006) indicates the production of CD-ROMs (step 24) after state recognition (step 23), which makes no sense in the 21st century.

Blanke indicates that only Esperanto succeeded to fulfil all the steps, as it shows, among the other indicators, evidence of organisation of big congresses ('big' meaning more than 1000 participants), official recognition (e.g., Esperanto is UNESCO Intangible Cultural Heritage of Croatia, Poland, and Europe 'as a carrier of Esperanto culture'), family speakers (already mentioned above), and overall original culture, including oral traits such as myths, rituals, and traditions, which entails language evolution. The main difference between awakening planned languages and Esperanto is that the latter is both recognised externally on various levels and in use internally in various domains, both formal and informal, in particular, in the domain of the family.

\section{Discussion and Concluding Remarks}

Sanguin (2020) argues that lesser-used languages across the European Union 'come up against a double wall', due to a move 'from a stage to resistance to a stage of tolerance and indifference'; the first wall is that they are anchored to their ancestral myth of authenticity, eventually reducing their appeal to non-heritage speakers, while the second wall is that they do not reach a critical mass, i.e., the number of speakers is relatively small. Digital resources eventually give a 'modern look' (Coluzzi 2005) to lesser-used languages, projecting them in present and future time, instead of being entrapped in the rhetorics of the "good ol' days" of authentic ancestry of the pre-digital world. In other words, coolification is a bridge that may pass through Sanguin's first wall, overcoming tolerance and indifference with, respectively, engagement and visibility.

On the other hand, the experience of internet-only Esperanto learners shows that coolification is necessary but not enough to sustain and nurture the community. The analysis of Piedmontese in comparison with Esperanto made by Gobbo and Miola (2016) suggests a possible line of research, which, unfortunately, is still underexplored in the literature. Esperanto does not easily fit current categories of analysis, being neither in danger, nor a minority language, stricto sensu. Rigorous comparison with other lesser-used language avoids the application of inappropriate categories of analysis and, therefore, severe and superficial judgement of "failure". In particular, while we assess language vitality, Esperanto shows that a non-threatened language can exist even if intergenerational transmission happens mainly outside family use. Finally, the initial ties formed through digital communication among learners of Esperanto online are challenging the tenets of the social movement, as they do necessarily bypass societies, associations, and organisations. However, this is not yet a stable alternative, which questions the future of the organisation of the social movement supporting the language, and, by extension, the social movements promoting less fortunate languages that may put too much hope into the role played by the digital realm to guarantee their survival.

A working hypothesis is that it is the appeal of the existing services provided by the social movement that channels the interest of the would-be new activists, bringing newcomers inside the social network (in the sense of SNT) and ultimately, transforming an online language learner into a new, real-world speaker through the establishment of weak and strong ties. How to reach this goal is unclear, even in the fortunate case of 
Esperanto, where neither any myth of ancestry nor specific territorialities are in place, easily overcoming any resistance to its use through digital means.

As a suggestion for further research, perhaps the limitations rely on the formal assumption behind the choice of proposing indexes and scales, as they imply the existence of one, and only one, definite line of progression, while the sociolinguistic reality of languages may require different formal representations: after all, there is no direct relation between informal domains such as family use and formal domains such as state recognition. We argue that the indicators of language vitality should give a solid explanation of the changes in the realm of language attitudes, in order to sustain language development; otherwise, they remain merely an academic exercise.

Funding: This research received no external funding.

Institutional Review Board Statement: Not applicable.

Informed Consent Statement: Not applicable.

Data Availability Statement: No new data were created or analyzed in this study. Data sharing is not applicable to this article.

Acknowledgments: I wish to thank the reviewers for their detailed comments and suggestions.

Conflicts of Interest: The author's Chair is funded by the Universal Esperanto Association. The funding institution had no role in the design of the study; in the collection, analyses, or interpretation of data; in the writing of the manuscript, or in the decision to publish the results.

\section{References}

Astori, Davide. 2016. Definire una minoranza socio-linguistica: Dalle lingue segnate a quelle pianificate. In Représentations Sociales des Langues et Politiques Linguistiques. Déterminismes, Implications, Regards Croisés. Edited by Agresti Giovanni and Turi Joseph-G. Rome: Aracne, pp. 195-222.

Astori, Davide. 2018. La rete delle lingue e la tutela delle identità. In Ecologia Della Rete. Per una Sostenibilità Delle Relazioni on Line. Edited by Pagnotta Fausto. Trento: Erickson, pp. 79-85.

Blanke, Detlev. 1985. Internationale Plansprachen. Eine Einführung. Berlin: Akademie Verlag.

Blanke, Detlev. 1989. Planned languages: A survey of the main problems. In Interlinguistics: Its Aims, Its Achievements and Its Place in Language Science. Edited by Klaus Schubert and Dan Maxwell. Berlin: Mouton de Gruyter, pp. 63-86.

Blanke, Detlev. 2006. Interlinguistische Beiträge. Zum Wesen und zur Funktion internationaler Plansprachen. Edited by Sabine Fiedler. Frankfurt/Main: Peter Lang.

Blom, Philipp. 2008. The Vertigo Years: Europe, 1900-1914. New York: Basic Books.

Caligaris, Irene. 2016. Una Lingua per Tutti, una Lingua di Nessun Paese. Una Ricerca sul Campo Sulle Identità Esperantiste. Roma: Aracne.

Ceberio, Klara, Antton Gurrutxaga, Claudia Soria, Irene Russo, and Valeria Quochi. 2018. How to Use the Digital Language Vitality Scale. Available online: http:/ / www.dldp.eu/sites/default/files/documents/DLDP_Digital-Language-Vitality-Scale. pdf (accessed on 10 May 2021).

Čeliauskas, Petras, and Konstantinas Puodènas. 2018. Didysis Lietuvių—Esperanto Kalbu Žodynas. Kaunas: Pasaulio Lietuvių Kultūros, Mokslo ir Švietimo Centras.

Coluzzi, Paolo. 2005. Pianificazione linguistica per la sopravvivenza delle lingue minoritarie. Cimbri-Tzimbar 33: 29-44.

Costa, James. 2015. New speakers, new language: On being a legitimate speaker of a minority language in Provence. International Journal of the Sociology of Language 231: 127-45. [CrossRef]

Daigneault, Anna Luisa, Daniel Bögre Udell, Kristen Tcherneshoff, and Gregory D. S. Anderson. 2020. Language Sustainability Kit. Version 3. Available online: livingtongues.org (accessed on 10 May 2021).

Dietterle, Johan. 1929. L. L. Zamenhof: Originala Verkaro. Ferdinand Hirt E Sohn. Leipzig: Esperanto-Fako.

Eco, Umberto. 1996. The Search for The Perfect Language. Oxford: Blackwell.

Ferguson, Charles A. 1982. Foreword. In The Other Tongue: English Across Cultures. Edited by Kachru Braj B. Urbana: University of Illinois Press.

Fettes, Mark. 1996. The Esperanto Community: A quasi-ethnic linguistic minority? Language Problems E Language Planning 20: 53-59. [CrossRef]

Fiedler, Sabine. 2012. The Esperanto denaskulo: The status of the native speaker of Esperanto within and beyond the planned language community. Language Problems E Language Planning 36: 69-84. [CrossRef]

First Peoples' Cultural Council. 2020. Check before You Tech! A Guide for Choosing Language Apps \& Software as Part of Your Plan to Reclaim, Revitalize and Maintain Your Indigenous Language. Available online: https:/ / fpcc.ca/wp-content/uploads/2020/0 9/FPCC-Check-Before-You-Tech.pdf (accessed on 10 May 2021). 
Fishman, Joshua. 1991. Reversing Language Shift: Theoretical and Empirical Foundations of Assistance to Threatened Language. Clevedon: Multilingual Matters.

Fishman, Joshua. 1996. Antaŭparolo/Prefazione: Minnaja, Carlo (red/acd). In Vocabolario Esperanto-Italiano. Milano: CoEdEs.

Forster, Peter G. 1982. The Esperanto Movement. The Hague: Mouton.

Garvía, Roberto. 2015. Esperanto and Its Rivals: The Struggle for an International Language. Philadelphia: University of Pennsylvania Press.

Gobbo, Federico. 2016. 'Lingvo Internacia' aŭ 'internacia lingvo'? Kelkaj konsideroj pri la origina nomo de Esperanto en diakrona perspektivo. In Prilingve en Nitro: Politike, Historie, Teorie, Instrue. Edited by Košecký Stanislav. Roterdamo: Universala Esperanto-Asocio, pp. 149-58.

Gobbo, Federico. 2017. Beyond the Nation-State? The Ideology of the Esperanto Movement between Neutralism and Multilingualism. Social Inclusion 5: 38-47. [CrossRef]

Gobbo, Federico, and Emanuele Miola. 2016. Modificare l'immagine linguistica: Esperanto e piemontese a confronto. In Représentations Sociales des Langues et Politiques Linguistiques. Déterminismes, Implications, Regards Croisés. Edited by Agresti Giovanni and Turi Joseph-G. Rome: Aracne, pp. 287-304.

Granovetter, Mark S. 1973. The Strength of Weak Ties. American Journal of Sociology 78: 1360-80. [CrossRef]

Haupenthal, Reinhard, ed. 1988. La Esperantisto. Gazeto por la Amikoj de la Lingvo Esperanto. 1889-1895. Hildeheim: Olms.

Kanzi, Ito [Ludovikito]. 1976. Hebreo el la Geto: De Cionismo al Hilelismo. Kyoto: Eldonejo Ludovikito.

Korzhenkov, Aleksander. 2010. The Life of Zamenhof. New York: Mondial.

Large, Andrew. 1985. The Artificial Language Movement. Oxford: Blackwell.

Lewis, M. Paul, and Gary F. Simons. 2010. Assessing endangerment: Expanding Fishman's GIDS. Revue Roumaine de Linguistique 55: 103-20.

Lyons, John. 1981. Language and Linguistics: An Introduction. Cambridge: Cambridge University Press.

Melnikov, Aleksandro S. 2015. Gvidlibro tra Esperantio. Rostov-na-Donu. Self-published. ISBN 978-5-98615-147-2.

Milroy, James. 2001. Language ideologies and the consequences of standardization. Journal of Sociolinguistics 5: 530-55. [CrossRef]

Miola, Emanuele. 2015. La tirannia della tastiera: Il caso dell'ortografia piemontese. Language Problems E Language Planning 39: 136-53.

Nielsen, Robert. 2020. Kie estas la Duolinganoj? Libera Folio, March 31. Available online: liberafolio.org/2020/03/31/kie-estas-laduolinganoj/ (accessed on 17 May 2021).

Rainer, Thom S., and Jess Rainer. 2011. The Millennials. Nashville: B\&H Publishing Group.

Sanguin, André-Louis. 2020. The Lesser Used Languages in the European Union: A Study in Political Geography. In Handbook of the Changing World Language Map. Edited by Stanley D. Brunn and Roland Kehrein. Cham: Springer. [CrossRef]

Schor, Esther. 2010. L. L. Zamenhof and the shadow people. Language Problems E Language Planning 34: 183-92.

Schor, Esther. Forthcoming. Ludwik Lejzer Zamenhof: Revisionist of Covenantal Judaism. In Language as Hope: L. L. Zamenhof and the Dream of a Cosmopolitan Wor(l)d. Edited by Beckmann Viola and Feierstein Liliana R. Leipzig: Heintrich \& Heintrich.

Smith, Chuck. 2015. Some Esperanto Course Statistics. Duolingo Forum, October 24. Available online: forum.duolingo.com/comment/ 11259457 /Some-Esperanto-course-statistics (accessed on 10 May 2021).

Stewart, William. 1968. A sociolinguistic typology for describing national multilingualism. Readings in the Sociology of Language 3: 531-45.

Tamburelli, Marco, and Mauro Tosco. 2021. What are contested languages and why should linguists care? In Contested Languages: The Hidden Multilingualism of Europe. Edited by Marco Tamburelli and Mauro Tosco. Amsterdam: John Benjamins.

van Dijk, Ziko. 2009. Wikipedia and lesser-user languages. Language Problems E Language Planning 33: 234-50.

Wennergren, Bertilo. 2021. Tekstaro de Esperanto. Last Check: Jan. Available online: tekstaro.com/tekstaro.html (accessed on 17 May 2021).

Zamenhof, Ludwik Lejzer. 1887. Международный язык. Warsaw: Kelter.

Zamenhof, Ludwik Lejzer. 1915. Post la Granda Milito. After the Great War. The British Esperantist 11: 51-54. 